\title{
Umbilical cord interleukin-6 predicts outcome in very low birthweight infants in a high HIV-burden setting: a prospective cohort study
}

\author{
Cheryl Anne Mackay $010,{ }^{1}$ James Stephanus Smit, ${ }^{2}$ Farhaad Khan, ${ }^{2}$ Fazana Dessai, ${ }^{3}$ \\ Catherine Connolly, ${ }^{3}$ Refiloe Masekela ${ }^{4}$
}

${ }^{1}$ Paediatrics Department, Dora Nginza Hospital, Port Elizabeth South Africa

${ }^{2}$ Paediatrics Department, Dora Nginza Hospital, Port Elizabeth Eastern Cape, South Africa

${ }^{3}$ University of KwaZulu-Natal, Durban, KwaZulu-Natal, South Africa

${ }^{4}$ Paediatrics and Child Health, University of KwaZulu-Natal College of Health Sciences, Durban, South Africa

\section{Correspondence to}

Dr Cheryl Anne Mackay,

Paediatrics Department, Dora Nginza Hospital, Port Elizabeth 6059, South Africa;

cmackay@mweb.co.za

Received 10 December 2019

Revised 13 March 2020

Accepted 4 April 2020

Published Online First

13 May 2020

\section{Check for updates}

\section{(c) Author(s) (or their} employer(s)) 2020. No commercial re-use. See rights and permissions. Published by BMJ.

To cite: Mackay CA, Smit JS, Khan F, et al. Arch Dis Child 2020;105:932-937.

\section{ABSTRACT}

Objectives South Africa has a double burden of high neonatal mortality and maternal HIV prevalence. Common to both is a proinflammatory in utero and perinatal milieu. The aim of this study was to determine cytokine profiles in HIV exposed (HE) and HIV unexposed (HU) very low birthweight (VLBW) infants and to determine whether these were associated with predischarge outcomes.

Design Single-centre, prospective cohort study conducted from 1 June 2017 to 31 January 2019.

Patients Inborn infants with birth weight of $<1500 \mathrm{~g}$ were enrolled and cord blood was collected for interleukin (IL)-6 and tumour necrosis factor alpha (TNF- $\alpha$ ) assays. Participants provided informed consent and ethics approval was obtained.

Outcome measures The primary outcome was umbilical cord cytokine levels according to maternal HIV status. Secondary outcomes included death and/or serious neonatal infection, necrotising enterocolitis, intraventricular haemorrhage, periventricular leucomalacia, chronic lung disease and haemodynamically significant patent ductus arteriosus before discharge.

Results A total of 279 cases were included with 269 cytokine assays performed on $122 \mathrm{HEs}$ and $147 \mathrm{HUs}$. Median IL-6 levels were $53.0 \mathrm{pg} / \mathrm{mL}$ in HEs and $21.0 \mathrm{pg} /$ $\mathrm{mL}$ in HUs $(p=0.07)$. Median TNF- $\alpha$ levels were $7.2 \mathrm{pg} /$ $\mathrm{mL}$ in HEs and $6.5 \mathrm{pg} / \mathrm{mL}$ in HUs $(p=0.6)$. There was significantly more late-onset sepsis in the HE group compared with the HU group (41.2\% vs $27.9 \%$ ) $(p=0.03)$. IL-6 levels were significantly higher for those with any adverse outcome $(p=0.006)$ and death and/or any adverse outcome ( $p=0.0001)$. TNF- $\alpha$ levels did not differ according to predischarge outcomes.

Conclusion There is no significant difference in IL-6 and TNF- $\alpha$ levels in cord blood of HE compared with HU VLBWs. However, IL-6 levels are significantly higher in VLBWs with adverse predischarge outcomes, and VLBW HEs are at increased risk of adverse predischarge outcomes compared with HUs, particularly late-onset sepsis.

\section{BACKGROUND}

The global community is committed to improving child health and reducing childhood mortality. Sustainable Development Goal 3.2 requires South Africa to reduce under-five mortality from 42.2 to $<25$ per 1000 live births and neonatal mortality

\section{What is already known on this topic?}

- Sepsis is an important cause of morbidity in very preterm infants.

- There is an increased risk of infectious morbidity in HIV exposed (HE) uninfected children, but this has not been well described in the neonatal population.

- Elevated proinflammatory cytokines in cord blood may be associated with neonatal sepsis and other adverse outcomes.

\section{What this study adds?}

- There is no difference between interleukin (IL)-6 and tumour necrosis factor alpha levels in $\mathrm{HE}$ compared with HIV unexposed (HU) very low birth weight (VLBW) infants.

- There is increased risk of late-onset sepsis in HE compared with HU VLBW infants.

- Elevated IL-6 levels in cord blood are associated with death, sepsis and adverse predischarge outcomes in HE and HU VLBW infants.

from 18.2 to $<12.0$ per 1000 live births between 2015 and 2030. ${ }^{12}$

Neonatal deaths are the largest contributor to under-five deaths worldwide. In 2015, complications of prematurity and neonatal encephalopathy became the leading causes of under-five deaths globally. ${ }^{1}$ Similarly, in South Africa, complications of preterm birth (36\%), intrapartum-related conditions (23\%) and infections (23\%) are the largest contributors to neonatal deaths. ${ }^{3}$

The burden of neonatal mortality in South Africa is compounded by a high prevalence of HIV with $23.7 \%$ of women of childbearing age reported to be HIV positive in $2019 .{ }^{4} \mathrm{HIV}$ positivity in pregnancy carries the risk of transmission from mother to child, as well as increased morbidity and mortality in HIV exposed (HE) uninfected infants. ${ }^{5}$ Advances in prevention of mother-to-child transmission have reduced transmission rates to $1.5 \%$ at 6 weeks of age, resulting in an increasing number of HE but uninfected infants who have increased morbidity and mortality compared with their unexposed counterparts. ${ }^{5-7}$ 


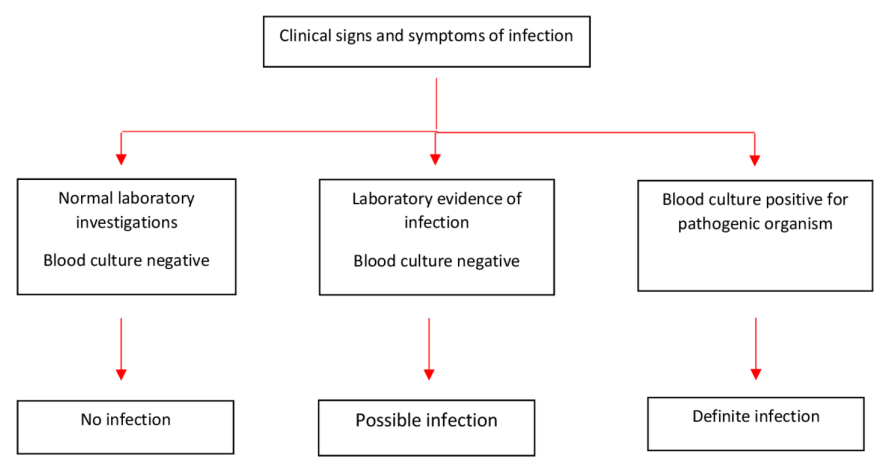

Figure 1 Definition of neonatal infection.

Common to both premature and HE infants is an altered inflammatory and immune environment in utero and perinatally. ${ }^{69}$ The role of a proinflammatory environment in both settings, independently and in the manner in which they interrelate, requires further investigation. The aim of this study was to determine whether proinflammatory cytokines interleukin-6 (IL-6) and tumour necrosis factor alpha (TNF- $\alpha$ ) differ between HE and unexposed very low birth weight (VLBW) infants and whether elevated levels of IL- 6 and TNF- $\alpha$ in umbilical cord blood are associated with adverse predischarge outcomes.

\section{METHODS}

A single-centre, prospective cohort study was conducted. Subjects were recruited from Dora Nginza Hospital, Port Elizabeth, between 1 June 2017 and 31 January 2019. Criteria for inclusion were mother-infant pairs delivered in the obstetric unit at the study site, birth weight of $<1500 \mathrm{~g}$, available placenta for obtaining cord blood and consent to participate in the study. Patients were excluded if they were not born at the study site, had one or more major congenital abnormalities, or refused consent.

Whole blood was collected from the umbilical cord following delivery of the placenta. Samples were stored at $0^{\circ} \mathrm{C}-4^{\circ} \mathrm{C}$ before

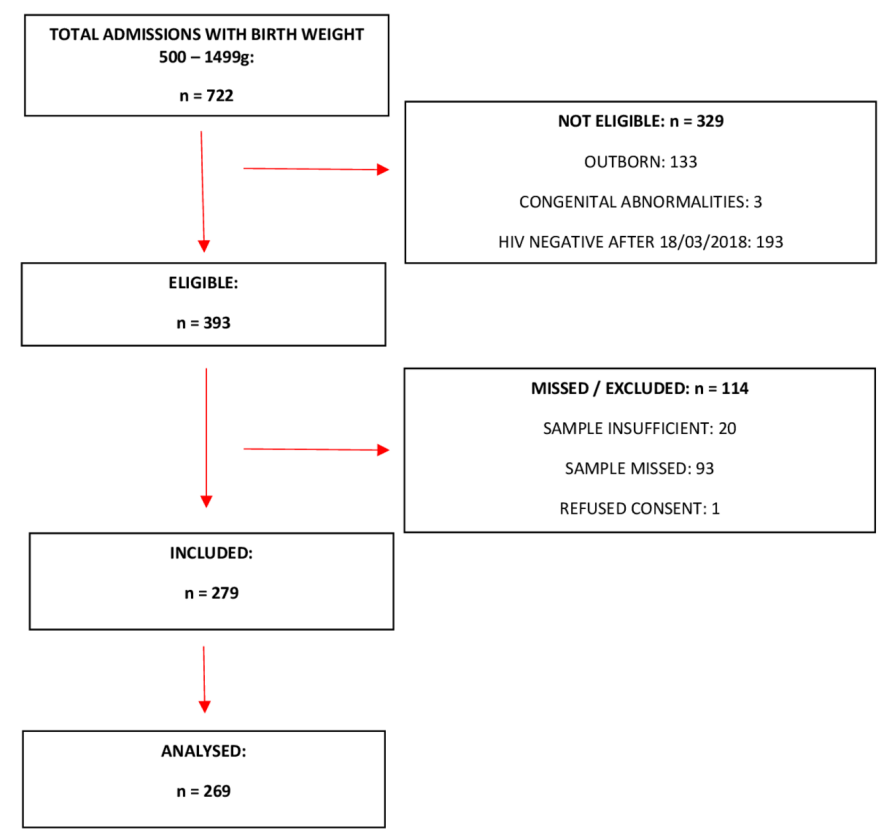

Figure 2 CONSORT diagram describing study sample selection and analysis. CONSORT, ConsolidatedStandards of Reporting Trials. transfer on ice to the National Health Laboratory Service within 6 hours of collection. They were centrifuged at $2000 \mathrm{~g}$ (Eppendorf 5702) for $10 \mathrm{~min}$, and the supernatant as stored at $-70^{\circ} \mathrm{C}$. Samples were couriered to the Health Sciences Research Laboratory at the University of KwaZulu-Natal, where IL-6 and TNF- $\alpha$ expression was analysed in duplicate using Quantikine ELISA immunoassay kits (R\&D Systems).

Detailed information was collected from the maternal folder, and patient outcome data were collected prospectively during hospital admission. The primary outcome was umbilical cord cytokine levels according to maternal HIV status.

Secondary outcomes included death and/or one of the following before discharge:

1. Serious neonatal infection based on clinical signs and laboratory investigations, including $\mathrm{C}$-reactive protein (CRP) of $>10 \mathrm{mg} / \mathrm{dL}$ and/or abnormal white cell count (WCC) (WCC $<5 \times 10^{9} / \mathrm{L}$ or WCC $>30 \times 10^{9} / \mathrm{L}$ in the first week of life or WCC $<5 \times 10^{9} / \mathrm{L}$ or $>20 \times 10^{9} / \mathrm{L}$ after the first week of life) and/or low platelet count (platelet count $<110 \times 10^{9} / \mathrm{L}$ in the first week of life or $<130 \times 10^{9} / \mathrm{L}$ after the first week of life). Early-onset infection was defined as infection occurring within the first 72 hours of life and late-onset infection as infection occurring beyond the first 72 hours of life. Investigations for neonatal infection were conducted based on clinical suspicion of the attending clinician. Serious neonatal infection was defined as definite, possible and no infection as described in figure 1. A skin commensal or nonsignificant organism was considered a significant isolate if the organism cultured recurrently and/or if there was laboratory evidence of infection.

2. Necrotising enterocolitis grade II or III according to the modified Bell staging system. ${ }^{10}$

3. Intraventricular haemorrhage grade III or four according to the Papile classification. ${ }^{11}$

4. Periventricular leucomalacia (PVL). ${ }^{12}$

5. Chronic lung disease defined as mild, moderate or severe according to the National Institutes of Health consensus definition. $^{13}$

6. Haemodynamically significant patent ductus arteriosus as described by McNamara and Sehgal. ${ }^{14}$

Secondary outcomes were analysed independently and as a composite of any adverse outcome defined as one or more of each individual outcome. Infants who were $\mathrm{HE}$ at birth and those who tested HIV PCR positive were managed according to the South African national consolidated guidelines for the prevention of mother-to-child transmission of HIV and the management of HIV in children, adolescents and adults. ${ }^{15}$

As the primary outcome of the study was descriptive in nature, the sample size of 248 infants (124 in each group) was required based on the secondary outcome, that is, death based on $80 \%$ power to detect a $50 \%$ difference in death between the two groups (estimated at $29.5 \%$ predischarge mortality) and/or the neonatal outcome with the lowest reported incidence (PVL estimated at 5\%) with a significance of $0.05 .^{16} 17$ Study data were analysed using STATA V.15.1 (Revision 2019). The Student t-test (two-tailed), Mann-Whitney U test, Wilcoxon rank-sum test, $\chi^{2}$ test and Fisher exact test were used for hypothesis testing.

Informed consent was obtained from the mother postdelivery.

\section{RESULTS}

A total of 722 neonates with birth weight of 500-1499 g were admitted to the neonatal unit at Dora Nginza Hospital during the study period. Of these, 279 cases were included in the study 
Table 1 Maternal clinical and demographic characteristics of the study sample $(\mathrm{N}=279)$

\begin{tabular}{|c|c|c|c|}
\hline Characteristic & $\begin{array}{l}\text { HIV exposed } \\
(n=131)\end{array}$ & $\begin{array}{l}\text { HIV unexposed } \\
(n=148)\end{array}$ & $P$ value \\
\hline Maternal age (mean, SD) & $30.0(6.0)$ & $26.6(6.3)$ & $<0.001$ \\
\hline Booked, n (\%) & $114(87.0)$ & $129(87.2)$ & 0.9 \\
\hline Local residence, $\mathrm{n}(\%)$ & $101(77.1)$ & $102(68.9)$ & 0.1 \\
\hline Parity (median, range) & $2.0(2-3)$ & $2.0(1-3)$ & $<0.001$ \\
\hline Gravidity (median, range) & $2.0(2-3)$ & $2.0(1-3)$ & 0.01 \\
\hline BMI (mean, SD) $(n=238)$ & $29.2(6.97)$ & $28.4(7.46)$ & 0.4 \\
\hline WR positive, $n(\%)(n=277)$ & $1(0.8)$ & $4(2.7)$ & 0.4 \\
\hline Rh positive, $\mathrm{n}(\%)$ & $131(100)$ & $147(99.3)$ & 0.9 \\
\hline \multicolumn{4}{|l|}{ HIV positive } \\
\hline Viral load (median, range) $(n=120)$ & $108(20-4205)$ & $\mathrm{N} / \mathrm{A}$ & \\
\hline HAART: yes, n (\%) & $117(90.0)$ & N/A & \\
\hline HAART: no, n (\%) & $8(6.2)$ & N/A & \\
\hline HAART: unknown/defaulted, n (\%) & $6(4.6)$ & $\mathrm{N} / \mathrm{A}$ & \\
\hline Hypertension, $\mathrm{n}(\%)^{*}$ & $47(35.9)$ & $80(54.1)$ & 0.002 \\
\hline Pre-eclampsia, $n(\%) \dagger$ & $43(32.8)$ & $65(43.9)$ & 0.1 \\
\hline Eclampsia, n (\%) & $3(2.3)$ & $9(6.1)$ & 0.1 \\
\hline HELLP, $n(\%)$ & $14(10.7)$ & $15(10.1)$ & 0.9 \\
\hline Diabetes, n (\%) & $1(0.8)$ & $11(7.4)$ & 0.006 \\
\hline Tuberculosis, n (\%) & $2(1.5)$ & $2(1.4)$ & 0.9 \\
\hline PROM, n (\%) & $12(9.2)$ & $5(3.4)$ & 0.05 \\
\hline Antepartum haemorrhage, $n(\%)$ & $19(14.5)$ & $17(11.5)$ & 0.5 \\
\hline \multicolumn{4}{|l|}{ Maternal infection, n (\%) } \\
\hline UTI & $2(1.5)$ & $8(5.4)$ & \\
\hline LRTI & $1(0.8)$ & $3(2.0)$ & \\
\hline GE & 0 & $1(0.7)$ & \\
\hline Any infection & $3(2.3)$ & $12(8.1)$ & 0.04 \\
\hline Smoking, n (\%) & $11(8.4)$ & $30(20.3)$ & 0.005 \\
\hline Drugs, n (\%) & $1(0.8)$ & 0 & 0.5 \\
\hline Alcohol, n (\%) & $30(22.9)$ & $28(18.9)$ & 0.4 \\
\hline Biomass exposure, $\mathrm{n}(\%)$ & $4(3.1)$ & $3(2.0)$ & 0.71 \\
\hline Chorioamnionitis, n (\%) & $2(1.5)$ & $2(1.4)$ & 0.9 \\
\hline Antenatal steroids, $\mathrm{n}(\%)$ & $60(45.8)$ & $76(51.4)$ & 0.4 \\
\hline Antenatal antibiotics, n (\%) & 18 (13.7) & $21(14.2)$ & 0.9 \\
\hline
\end{tabular}

*Isolated high blood pressure.

tHigh blood pressure associated with proteinuria, thrombocytopenia, coagulopathy and/or deranged liver enzymes.

BMI, body mass index; GE, gastroenteritis; HAART, highly active antiretroviral treatment; HELLP syndrome, haemolysis, elevated liver enzymes and low platelets; LRTI, lower respiratory tract infection; N/A, not applicable; PROM, prolonged rupture of membranes; Rh, Rhesus; UTI, urinary tract infection; WR, Wassermann reaction.

as outlined in the Consolidated Standards of Reporting Trials (CONSORT) diagram in figure 2. The total sample of infants born to HIV-negative mothers was complete by 18 March 2018, after which time only infants born to HIV-positive women were included. At the time of analysis, two samples were inadequate, and there were eight samples that could not be analysed due to insufficient cytokine assay kits. Results of 269 participants were included in the final analysis, of which 122 were HE (76 samples collected before 31 March 2018 and the remaining 46 samples collected after 31 March 2018) and 147 were HIV unexposed (HU). A number of eligible cases for the study were excluded as a result of samples being insufficient or missed. HIV exposure in samples not included before 31 March 2018 was unknown in 2 cases, exposed in 26 cases and unexposed in 42 cases, and in those collected after 31 March 2018, HIV exposure was unknown in four cases and exposed in the remaining 46. Certain basic characteristics of the group of cases included were compared with those not included in order to exclude bias. There was no difference in birth weight, sex or survival to discharge between the two groups. However, a significantly
Table 2 Neonatal clinical and demographic characteristics of the study sample $(\mathrm{N}=279)$

\begin{tabular}{|c|c|c|c|}
\hline Characteristic & HE $(n=131)$ & HU $(n=148)$ & $P$ value \\
\hline Gestational age (mean, SD) & $29.4(2.3)$ & $29.6(2.6)$ & 0.5 \\
\hline \multicolumn{4}{|l|}{ Mode of delivery, $n(\%)$} \\
\hline $\mathrm{C} / \mathrm{S}$ & $73(55.7)$ & $87(58.8)$ & 0.6 \\
\hline Vaginal delivery & $58(44.3)$ & $61(41.2)$ & \\
\hline \multicolumn{4}{|l|}{ Sex, n (\%) } \\
\hline M & $63(48.1)$ & $71(48.0)$ & 0.9 \\
\hline $\mathrm{F}$ & $68(51.9)$ & $77(52.0)$ & \\
\hline Birth weight (g) (median, range) & $1200(900-1345)$ & $1122(937-1312)$ & 0.7 \\
\hline Birth length $(\mathrm{cm})$ (median, range) & $37.0(34-39)$ & $37.3(35-39)$ & 0.5 \\
\hline $\begin{array}{l}\text { Birth head circumference }(\mathrm{cm}) \\
\text { (mean, SD) }\end{array}$ & $26.4(2.12)$ & $26.8(1.79)$ & 0.1 \\
\hline \multicolumn{4}{|l|}{ Weight for gestational age, $\mathrm{n}(\%)$} \\
\hline AGA & $109(83.2)$ & $120(81.1)$ & 0.9 \\
\hline LGA & $1(0.8)$ & $2(1.4)$ & \\
\hline SGA & $21(16.0)$ & $26(17.6)$ & \\
\hline \multicolumn{4}{|l|}{$\mathrm{HE}, \mathrm{n}(\%)$} \\
\hline PCR positive & $2(1.5)$ & $N / A$ & \\
\hline PCR negative & $118(90.1)$ & N/A & \\
\hline PCR not done/rejected & $11(8.4)$ & $N / A$ & \\
\hline \multicolumn{4}{|l|}{ Apgar score, $\mathrm{n}(\%)$} \\
\hline $1 \min \leq 6$ & $57(43.8)$ & $57(38.5)$ & 0.4 \\
\hline $5 \min \leq 6$ & $20(15.4)$ & $18(12.2)$ & 0.4 \\
\hline $10 \min \leq 6$ & $8(6.2)$ & $6(4.1)$ & 0.4 \\
\hline \multicolumn{4}{|l|}{ Resuscitation, n (\%) } \\
\hline None & $76(58.0)$ & $92(62.2)$ & 0.5 \\
\hline BMV & $55(42.0)$ & $56(37.8)$ & \\
\hline Chest compressions & $7(5.3)$ & $11(7.4)$ & \\
\hline Adrenalin & $3(2.3)$ & $3(2.0)$ & \\
\hline \multicolumn{4}{|l|}{ Feeds, n (\%) } \\
\hline Breast milk & $130(99.2)$ & $148(100)$ & 0.5 \\
\hline Formula & $1(0.8)$ & & \\
\hline \multicolumn{4}{|l|}{ Central line, n (\%) } \\
\hline UVL & $8(6.1)$ & $10(6.8)$ & \\
\hline CVP & $4(3.1)$ & $5(3.4)$ & \\
\hline UVL and/or CVP & $12(9.2)$ & $15(10.1)$ & 0.8 \\
\hline \multicolumn{4}{|l|}{ Ventilation, n (\%) } \\
\hline CPAP & $90(68.7)$ & $97(65.5)$ & \\
\hline IPPV & $23(17.6)$ & $33(22.3)$ & \\
\hline CPAP and/or IPPV & $91(69.5)$ & $97(65.5)$ & 0.5 \\
\hline TPN & $4(3.1)$ & $2(1.4)$ & 0.4 \\
\hline $\begin{array}{l}\text { Length of hospital stay (days) } \\
\text { (median, range) }\end{array}$ & $27(13-40)$ & $28(14-44)$ & 0.3 \\
\hline
\end{tabular}

AGA, appropriate for gestational age; BMV, bag and mask ventilation; CPAP, continuous positive airway pressure; $C / S$, caesarean section; CVP, central venous line; F, female; HE, HIV exposed; HU, HIV unexposed; IPPV intermittent positive airway pressure; LGA, large for gestational age; M, male; SGA, small for gestational age; TPN, total parenteral nutrition; UVL, umbilical venous line.

larger number of cases that were missed had a $10 \mathrm{~min}$ Apgar score of $\leq 6$ (15.4\% vs 5.0\%, p=0.001).

Maternal clinical and demographic characteristics are outlined in table 1. Maternal age was significantly higher in the group of HE compared with HU VLBW infants (30.0 vs 26.6 years, $\mathrm{p}<0.001)$, and the HIV-positive mothers had significantly higher parity and gravidity $(\mathrm{p}<0.001$ and $\mathrm{p}=0.01$, respectively). Hypertension $(38.2 \%$ vs $54.1 \%, \mathrm{p}=0.009)$, diabetes $(0.8 \%$ vs $7.4 \%, p=0.008)$ and cigarette smoking $(7.3 \%$ vs $20.3 \%$, $\mathrm{p}=0.002$ ) were more common in HIV-negative mothers.

Neonatal clinical and demographic characteristics are outlined in table 2. There was no significant difference between HE compared with HU VLBW infants in relation to gestational age, 
Table 3 Predischarge outcomes of HE and HU VLBW infants according to umbilical cord IL- 6 and TNF- $\alpha$ levels $(n=269)$

\begin{tabular}{|c|c|c|c|c|c|c|c|c|}
\hline \multirow[b]{3}{*}{ Outcome/characteristic } & \multicolumn{4}{|c|}{ IL-6 (pg/mL } & \multicolumn{4}{|c|}{ TNF- $\alpha(p g / m L)$} \\
\hline & \multirow{2}{*}{$\frac{n}{269}$} & \multirow{2}{*}{$\begin{array}{l}\text { Median } \\
36.8\end{array}$} & \multirow{2}{*}{$\frac{\mathrm{IQR}}{7-300}$} & \multirow[b]{2}{*}{$P$ value } & \multirow{2}{*}{$\frac{n}{269}$} & \multirow{2}{*}{$\begin{array}{l}\text { Median } \\
6.6\end{array}$} & \multirow{2}{*}{$\frac{\mathrm{IQR}}{1-15}$} & \multirow[b]{2}{*}{$P$ value } \\
\hline & & & & & & & & \\
\hline \multicolumn{9}{|l|}{ HIV status } \\
\hline Exposed & 122 & 53 & $8-300$ & 0.07 & 122 & 7.2 & $1-18$ & 0.6 \\
\hline Not exposed & 147 & 21 & $6-181$ & & 147 & 6.5 & $1-14$ & \\
\hline \multicolumn{9}{|l|}{ Survival to discharge: } \\
\hline Survived & 196 & 33.4 & $7-282$ & 0.3 & 196 & 6.4 & $1-15$ & 0.9 \\
\hline Died & 73 & 38.4 & $9-300$ & & 73 & 6.9 & $1-16$ & \\
\hline \multicolumn{9}{|l|}{ IVH III/IV } \\
\hline Yes & 10 & 68.6 & $13-300$ & 0.8 & 10 & 9 & $1-23$ & 0.6 \\
\hline No & 252 & 37.1 & $7-300$ & & 252 & 6.7 & $1-15$ & \\
\hline \multicolumn{9}{|l|}{ PVL } \\
\hline Yes & 2 & 162.9 & $26-300$ & 0.4 & 2 & 4.8 & $1-9$ & 0.5 \\
\hline No & 265 & 37 & $7-300$ & & 265 & 6.6 & $1-15$ & \\
\hline \multicolumn{9}{|l|}{ CLD } \\
\hline Yes & 21 & 64.9 & $1-300$ & 0.5 & 21 & 13.4 & $1-35$ & 0.2 \\
\hline No & 248 & 31.8 & $7-261$ & & 248 & 6.4 & $1-15$ & \\
\hline \multicolumn{9}{|l|}{ NEC II/III } \\
\hline Yes & 23 & 40.1 & $12-300$ & 0.4 & 23 & 13.3 & $1-24$ & 0.2 \\
\hline No & 246 & 35.4 & $7-300$ & & 246 & 6.5 & $1-15$ & \\
\hline \multicolumn{9}{|l|}{ Sepsis } \\
\hline None & 131 & 20.7 & $6-162$ & 0.09 & 131 & 6.2 & $1-14$ & 0.2 \\
\hline Possible & 94 & 59.4 & $12-300$ & & 94 & 6.5 & $1-16$ & \\
\hline Definite & 44 & 26.5 & $9-300$ & & 44 & 8.9 & $1-22$ & \\
\hline \multicolumn{9}{|l|}{ hsPDA } \\
\hline No & 225 & 36.8 & $7-258$ & 0.6 & 225 & 6.3 & $1-15$ & 0.3 \\
\hline Yes & 44 & 37.2 & $10-300$ & & 44 & 9 & $1-18$ & \\
\hline \multicolumn{9}{|l|}{ Any adverse outcome } \\
\hline Yes & 156 & 51.8 & $11-300$ & 0.006 & 156 & 6.9 & $1-18$ & 0.3 \\
\hline No & 113 & 18.4 & $5-135$ & & 113 & 6.2 & $1-14$ & \\
\hline \multicolumn{9}{|c|}{ Death and/or any adverse outcome } \\
\hline Yes & 179 & 59.6 & $10-300$ & 0.0001 & 179 & 7.5 & $1-18$ & 0.1 \\
\hline No & 90 & 13.9 & $5-66$ & & 90 & 5.7 & $1-13$ & \\
\hline
\end{tabular}

Bold-faced values in table 3 denote values that are statistically significant.

CLD, chronic lung disease; HE, HIV exposed; hSPDA, haemodynamically significant patent ductus arteriosus; HU, HIV unexposed; IL, interleukin; IVH, intraventricular haemorrhage; NEC, necrotising enterocolitis; PVL, periventricular leucomalacia; TNF- $\alpha$, tumour necrosis factor alpha; VLBW, very low birth weight.

birth weight, gender distribution, mode of delivery or other important clinical characteristics.

IL-6 and TNF- $\alpha$ results and corresponding predischarge outcomes of the study sample are presented in table 3. IL-6 levels were higher in HE compared with HU VLBW infants, but this did not reach statistical significance. IL-6 levels were significantly higher for the combined outcome of any adverse outcome $(p=0.006)$ and the combined outcome of death and/ or any adverse outcome $(\mathrm{p}=0.0001)$. There was no significant difference in IL- 6 levels for any other predischarge outcomes, and there was no significant difference in TNF- $\alpha$ levels for the predetermined predischarge outcomes.

The outcomes of HE compared with HU VLBW infants at the time of discharge or transfer out of the neonatal unit are presented in table 4 . There was significantly more late-onset sepsis in HE than HU infants: $41.2 \%$ of the HE group developed possible or definite late-onset sepsis compared with $27.9 \%$ of the HU group ( $\mathrm{p}=0.02$ ). There were 60 isolates in 46 patients with definite sepsis, of which 28 were $\mathrm{HE}$ and 18 were HU. Thirty-five organisms were cultured in the HE group, including Acinetobacter baumanii, ${ }^{11}$ Klebsiella pneumoniae, ${ }^{10}$ Enterobacter cloacae, ${ }^{4}$ Enterococcus faecium, ${ }^{3}$ Psendomonas aeruginosa ${ }^{2}$ Escherichia coli, ${ }^{1}$ Streptococcus agalactiae, ${ }^{1}$ Listeria monocytogenes, ${ }^{1}$ Candida albicans ${ }^{1}$ and Candida parapsilosis. ${ }^{1}$
Twenty-five organisms were cultured in the HU group including K. pneumoniae ${ }^{8}$ A. baumanii, ${ }^{5}$ E. cloacae,${ }^{2}$ E. faecium, ${ }^{1}$ P. aeruginosa,${ }^{1}$ Staphylococcus aureus, ${ }^{2}$ S. epidermidis, ${ }^{1}$ S. agalactiae, ${ }^{1}$ C. parapsilosis ${ }^{4}$ and one unidentified yeast. ${ }^{1}$ There were 107 patients and 116 episodes of possible sepsis. Of these, 55 were based on abnormal full blood count (FBC), 41 on elevated CRP and 20 on both abnormal FBC and CRP.

Not all the HE and HU cases were recruited at the same time. In order to adjust for confounding factors, a subanalysis of possible and/or definite late-onset sepsis in HE versus HU infants was conducted for the period during which samples for the two groups were collected contemporaneously. There was still significantly more late-onset sepsis in HE (35\%) compared with HU $(28 \%)$ infants $(\mathrm{p}=0.02)$.

\section{DISCUSSION}

The current study found no significant difference in cord blood IL- 6 and TNF- $\alpha$ levels between HE and HU infants, and the wide range of cytokine assay values is notable. There were, however, several differences in maternal characteristics between $\mathrm{HE}$ and HU infants. Maternal age, parity and gravidity were significantly higher in the HE compared with the HU group. This likely represents an increased risk of HIV transmission in women with 
Table 4 Predischarge outcomes of VLBW infants according to maternal HIV status $(n=279)$

\begin{tabular}{|c|c|c|c|c|c|}
\hline \multirow[b]{2}{*}{ Outcome } & \multicolumn{2}{|c|}{$\begin{array}{l}\text { HIV exposed } \\
(n=131)\end{array}$} & \multicolumn{2}{|c|}{$\begin{array}{l}\text { HIV unexposed } \\
(n=148)\end{array}$} & \multirow[b]{2}{*}{$P$ value } \\
\hline & no & $\%$ & no & $\%$ & \\
\hline Survival to discharge & 92 & 70.2 & 111 & 75 & 0.4 \\
\hline IVH III/IV & 122 & 96.8 & 140 & 95.9 & 0.8 \\
\hline PVL & 1 & 0.8 & 1 & 0.7 & 0.9 \\
\hline CLD & 8 & 6.1 & 13 & 8.8 & 0.9 \\
\hline NEC II/III & 15 & 11.5 & 8 & 5.4 & 0.07 \\
\hline \multicolumn{6}{|l|}{ Early-onset sepsis } \\
\hline None & 105 & 80.8 & 106 & 71.6 & 0.2 \\
\hline Possible & 22 & 16.9 & 37 & 25 & \\
\hline Definite & 3 & 2.3 & 4 & 2.7 & \\
\hline \multicolumn{6}{|l|}{ Late-onset sepsis } \\
\hline None & 77 & 58.8 & 106 & 72.1 & 0.03 \\
\hline Possible & 29 & 22.1 & 27 & 18.4 & \\
\hline Definite & 25 & 19.1 & 14 & 9.5 & \\
\hline \multicolumn{6}{|l|}{ Any sepsis } \\
\hline None & 61 & 46.6 & 77 & 52.4 & 0.12 \\
\hline Possible & 42 & 32.1 & 53 & 36.1 & \\
\hline Definite & 28 & 21.4 & 18 & 12.2 & \\
\hline hsPDA & 22 & 16.8 & 24 & 16.2 & 0.9 \\
\hline Any adverse outcome ${ }^{*}$ & 80 & 61.1 & 82 & 55.4 & 0.3 \\
\hline Death and/or any adverse outcome & 92 & 70.2 & 95 & 64.2 & 0.3 \\
\hline Time to discharge (median, range) & 27 & $13-40$ & 28 & $0-44$ & 0.3 \\
\hline
\end{tabular}

*Any adverse outcome defined as IVH and/or PVL and/or CLD and/or NEC II/III and/or early-onset sepsis and/or late-onset sepsis and/or hsPDA.

CLD, chronic lung disease; hsPDA, haemodynamically significant patent ductus arteriosus; IVH, intraventricular haemorrhage; NEC, necrotising enterocolitis; PVL, periventricular leucomalacia; VLBW, very low birth weight.

increasing age and exposure. Hypertension, diabetes and cigarette smoking were more common in HIV-negative mothers, which may reflect differences in pathophysiology of prematurity between HIV-positive and HIV-negative pregnant women in middle-income countries. ${ }^{18} 19$ The findings of significantly higher IL-6 levels in patients with any adverse outcome and the combined outcome of death and/or any adverse outcome require further exploration.

With the wide variation in cytokine levels in the HE and HU infants, it is noted that the median for both the groups was higher in this population than that proposed in previous studies, with an IL-6 level of $>11 \mathrm{pg} / \mathrm{mL}$ on cord blood proposed to define foetal inflammatory response syndrome. ${ }^{20}$ This could be explained by the large proportion $(51.3 \%)$ of patients in the study population with possible and/or definite sepsis. The literature suggests that cytokine levels are significantly lower in neonates than older children and adults and significantly higher in umbilical cord blood compared with patient samples. ${ }^{21}$ However, the majority of normal values are based on adult studies, with relatively little data from paediatric and neonatal populations, and normal ranges are generally wide. ${ }^{21}$

In the current study, higher IL-6 levels were found in patients with any adverse outcome and the combined outcome of death and/or any adverse outcome. Although interesting and worthy of further exploration, these outcomes were not the primary focus of the study and were the result of several subanalyses. The statistical effect of this needs to be kept in mind. In addition, they were based on composite outcomes which, although beneficial in improving statistical efficiency, require care in interpretation due to the variable impact of each individual component. ${ }^{22}$ Relative clinical importance, frequency and significance of results for individual component outcomes need to be taken into consideration in the interpretation. ${ }^{22}$ In balancing the interpretation of factors, it is felt that use of composite outcomes in this study provides clinically relevant information regarding the effect of a proinflammatory milieu on outcome of VLBW infants as long as the strengths and weaknesses of this approach are understood.

Significantly more late-onset sepsis in the group of $\mathrm{HE}$ compared with HU infants is an additional secondary outcome reported. The risk of infectious morbidity in $\mathrm{HE}$ patients has been well described in older infants. ${ }^{23-27}$ Infections are also more severe, have a higher rate of treatment failure and increased risk of complications in HE infants. ${ }^{2526-32}$ Specific to the neonatal population, infection with $S$. agalactiae is more common and more severe in $\mathrm{HE}$ than $\mathrm{HU}$ infants, but no other differences in early-onset and/or late-onset bacterial sepsis in the newborn have been reported. ${ }^{3233}$ This is, to the best of our knowledge, the first report of increased late-onset sepsis in VLBW HE compared with HU infants.

The pathophysiology of increased infectious morbidity in $\mathrm{HE}$ infants is multifactorial, comprising both antenatal and postnatal factors. Antenatal exposure to microbial components, maternal coinfections, a proinflammatory in utero environment and exposure to maternal antiretroviral therapy result in immunodeficiency from T-cell dysfunction, reduced transplacental transfer of antibodies, immune activation, infant coinfection and impaired foetal growth. ${ }^{34} 35$ Postpartum transmission of maternal infections, altered maternal colonisation with microorganisms and transfer of these to the infant, and exposure to HIV and viral components in breast milk with resultant enteropathy lead to chronic inflammation in the HE infant. ${ }^{3435}$

The strengths of this study include the reporting of important findings regarding predischarge outcomes of HE VLBW infants, as well as the effect of a proinflammatory intrauterine and perinatal milieu. The generalisability of the findings is, however, limited by the single-centre study design and requires corroboration with studies from other centres. An additional weakness is the comparison of characteristics of samples collected versus samples missed, which showed a significantly larger number of missed cases with a 10 min Apgar score of $\leq 6$. These patients required extensive resuscitation at birth with the result that cord blood could not be collected simultaneously. Although unavoidable at the time, this does lead to the exclusion of high-risk cases that may have affected the study results.

\section{CONCLUSION}

There is no significant difference in IL- 6 and TNF- $\alpha$ levels in cord blood of HE compared with HU VLBW infants. IL-6 levels in cord blood are, however, significantly higher in VLBW infants with adverse predischarge outcomes, and HE VLBW infants are noted to be at increased risk of late-onset sepsis compared with HUs regardless of IL- 6 levels. The association of increased infectious morbidity in HE VLBW infants is an important new finding, the pathophysiology of which requires further investigation.

Contributors CAM: protocol development, data collection and writing of the manuscript. RM: protocol development and writing/revision of the manuscript. JSS: data collection and review of the manuscript. FK: data collection. FD: data collection, responsible for cytokine assays, manuscript review and revision. CC: statistical analysis.

Funding The study was funded by the University of KwaZulu-Natal, the Discovery Foundation and the South African Medical Research Council.

Competing interests None declared.

Patient consent for publication Not required. 
Ethics approval Ethics approval was obtained from the Biomedical Research Ethics Committee of the University of KwaZulu-Natal (BE632/16), the Human Research Ethics Committee of Walter Sisulu University (003/2017) and the Eastern Cape Department of Health (EC_2017RP58_14).

Provenance and peer review Not commissioned; externally peer reviewed.

Data availability statement Data are available upon reasonable request. Original data, in the form of deidentified participant data, are available upon reasonable request from the primary corresponding author (Dr Cheryl Mackay; email cmackay@mweb.co.za).

ORCID iD

Cheryl Anne Mackay http://orcid.org/0000-0002-4966-4911

\section{REFERENCES}

1 GBD 2015 Child Mortality Collaborators. Global, regional, National, and selected subnational levels of stillbirths, neonatal, infant, and under-5 mortality, 19802015: a systematic analysis for the global burden of disease study 2015. Lancet 2016;388:1725-74.

2 United Nations. Transforming our world: the 2030 agenda for sustainable development, 2015. Available: https://sustainabledevelopment.un.org/post2015/ transformingourworld

3 Rhoda N, Velaphi S, Gebhardt GS, et al. Reducing neonatal deaths in South Africa: progress and challenges. S Afr Med J 2018;108:9-16.

4 UNAIDS. UNAIDS 2019, 2019. Available: https://aidsinfo.unaids.org/

5 Treatment Action Campaign. Summary of HIV statistics for South Africa, 2008. Available: https://tac.org.za/news/key-hiv-statistics

6 Evans C, Jones CE, Prendergast AJ. Hiv-Exposed, uninfected infants: new global challenges in the era of paediatric HIV elimination. Lancet Infect Dis 2016;16:e92-107.

7 SANAC. Let our actions count: reflections on NSP 2012 - 2016 and moving forward to NSP 2017 - 2022. SANAC, 2019.

8 Goepfert AR, Andrews WW, Carlo W, et al. Umbilical cord plasma interleukin-6 concentrations in preterm infants and risk of neonatal morbidity. Am J Obstet Gynecol 2004;191:1375-81.

9 Weeks JW, Reynolds L, Taylor D, et al. Umbilical cord blood interleukin-6 levels and neonatal morbidity. Obstet Gynecol 1997;90:815-8.

10 Lee JS, Polin RA. Treatment and prevention of necrotizing enterocolitis. Semin Neonatol 2003;8:449-59.

11 Papile LA, Burstein J, Burstein R, et al. Incidence and evolution of subependymal and intraventricular hemorrhage: a study of infants with birth weights less than 1,500 GM. J Pediatr 1978:92:529-34.

12 Ment LR, Bada HS, Barnes P, et al. Practice parameter: neuroimaging of the neonate: report of the Quality Standards Subcommittee of the American Academy of Neurology and the practice Committee of the child Neurology Society. Neurology 2002; 58:1726-38.

13 Jobe AH, Bancalari E. Bronchopulmonary dysplasia. Am J Respir Crit Care Med 2001;163:1723-9.

14 McNamara PJ, Sehgal A. Towards rational management of the patent ductus arteriosus: the need for disease staging. Arch Dis Child Fetal Neonatal Ed 2007:92:F424-7.

15 National Department of Health. Paediatric Hospital level: standard treatment guidelines and essential medicines list for South Africa. 4th edn. Pretoria, South Africa: National Department of Health, 2017.
16 Ballot DE, Chirwa TF, Cooper PA. Determinants of survival in very low birth weight neonates in a public sector hospital in Johannesburg. BMC Pediatr 2010;10:30.

17 Lemons JA, Bauer CR, Oh W, et al. Very low birth weight outcomes of the National Institute of child health and human development neonatal research network, January 1995 through December 1996. NICHD neonatal research network. Pediatrics 2001;107:E1.

18 Obimbo MM, Zhou Y, McMaster MT, et al. Placental structure in preterm birth among HIV-positive versus HIV-negative women in Kenya. J Acquir Immune Defic Syndr 2019;80:94-102

19 Goldenberg RL, Culhane JF, lams JD, et al. Epidemiology and causes of preterm birth. Lancet 2008;371:75-84.

20 Gotsch F, Romero R, Kusanovic JP, et al. The fetal inflammatory response syndrome. Clin Obstet Gynecol 2007;50:652-83.

21 Decker M-L, Grobusch MP, Ritz N. Influence of age and other factors on cytokine expression profiles in healthy Children-A systematic review. Front Pediatr 2017;5:255.

$22 \mathrm{McCoy}$ CE. Understanding the use of composite endpoints in clinical trials. West $\mathrm{J}$ Emerg Med 2018;19:631-4.

23 Koyanagi A, Humphrey JH, Ntozini R, et al. Morbidity among human immunodeficiency virus-exposed but uninfected, human immunodeficiency virusinfected, and human immunodeficiency virus-unexposed infants in Zimbabwe before availability of highly active antiretroviral therapy. Pediatr Infect Dis $J$ 2011:30:45-51.

24 Mussi-Pinhata MM, Freimanis L, Yamamoto AY, et al. National Institute of child health and human development international site development initiative perinatal Study Group. infectious disease morbidity among young HIV-1-exposed but uninfected infants in Latin American and Caribbean countries: the National Institute of child health and human development international site development initiative perinatal study. Pediatrics 2007;119:e694-794.

25 Slogrove AL, Cotton MF, Esser MM. Severe infections in HIV-exposed uninfected infants: clinical evidence of immunodeficiency. J Trop Pediatr 2010;56:75-81.

26 Slogrove A, Reikie B, Naidoo S, et al. Hiv-Exposed uninfected infants are at increased risk for severe infections in the first year of life. J Trop Pediatr 2012:58:505-8.

27 Hoffmann KS, Green RJ. Candida perforation of the intestine in an HIV-exposed but uninfected infant. S Afr J CH 2014;8:119-21.

28 Izadnegahdar R, Fox MP, Jeena P, et al. Revisiting pneumonia and exposure status in infants born to HIV-infected mothers. Pediatr Infect Dis J 2014:33:70-2.

29 McNally LM, Jeena PM, Gajee K, et al. Effect of age, polymicrobial disease, and maternal HIV status on treatment response and cause of severe pneumonia in South African children: a prospective descriptive study. Lancet 2007;369:1440-51.

30 Kelly MS, Wirth KE, Steenhoff AP, et al. Treatment failures and excess mortality among HIV-exposed, uninfected children with pneumonia. J Pediatric Infect Dis Soc 2015;4:e117-26.

31 Karpelowsky JS, Millar AJW, van der Graaf N, et al. Outcome of HIV-exposed uninfected children undergoing surgery. BMC Pediatr 2011;11:69.

32 Slogrove AL, Goetghebuer T, Cotton MF, et al. Pattern of infectious morbidity in HIVexposed uninfected infants and children. Front Immuno/ 2016;7:164.

33 Cutland CL, Schrag SJ, Zell ER, et al. Maternal HIV infection and vertical transmission of pathogenic bacteria. Pediatrics 2012;130:e581-90.

34 Evans C, Humphrey JH, Ntozini R, et al. Hiv-Exposed uninfected infants in Zimbabwe: insights into health outcomes in the Pre-Antiretroviral therapy era. Front Immunol 2016;7:190.

35 Afran L, Garcia Knight M, Nduati E, et al. Hiv-Exposed uninfected children: a growing population with a vulnerable immune system? Clin Exp Immunol 2014;176:11-22. 